\title{
REVIEW
}

\section{Determinants of Axon Growth, Plasticity, and Regeneration in the Context of Spinal Cord Injury}

\author{
Angela R. Filous* and Jan M. Schwab* ${ }^{\star \dagger \S}$
}

From the Spinal Cord Injury Division, ${ }^{*}$ Department of Neurology, the Departments of Neuroscience ${ }^{\dagger}$ and Physical Medicine and Rehabilitation, ${ }^{\ddagger}$ and the Center for Brain and Spinal Cord Repair, ${ }^{\S}$ Spinal Cord Injury Medicine, The Ohio State University, Wexner Medical Center, Columbus, Ohio

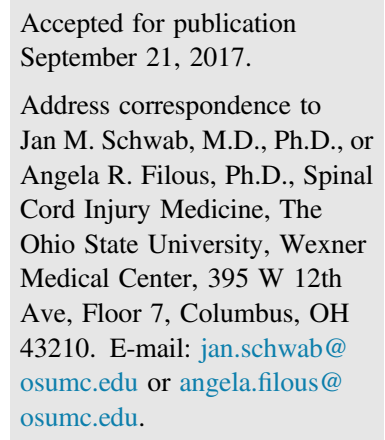

\begin{abstract}
The mechanisms that underlie recovery after injury of the central nervous system have rarely been definitively established. Axon regrowth remains the major prerequisite for plasticity, regeneration, circuit formation, and eventually functional recovery. The attributed functional relevance of axon regrowth, however, will depend on several subsequent conditional neurobiological modifications, including myelination and synapse formation, but also pruning of aberrant connectivity. Despite the ability to revamp axon outgrowth by altering an increasing number of extracellular and intracellular targets, disentangling which axons are responsible for the recovery of function from those that are functionally silent, or even contributing to aberrant functions, represents a pertinent void in our understanding, challenging the intuitive translational link between anatomical and functional regeneration. Anatomic hallmarks of regeneration are not static and are largely activity dependent. Herein, we survey mechanisms leading to the formation of dystrophic growth cone at the injured axonal tip, the subsequent axonal dieback, and the molecular determinants of axon growth, plasticity, and regeneration in the context of spinal cord injury. (Am J Pathol 2018, 188: 53-62; https://doi.org/10.1016/j.ajpath.2017.09.005)
\end{abstract}

During development, the axons of the central nervous system (CNS) form an elaborate circuitry. These axons fail to regenerate after injury in the adult CNS (Figure 1), with the exception of the olfactory sensory projections within the olfactory bulb, monoaminergic axons of the mediobasal hypothalamus, ${ }^{3}$ and serotonergic axons. ${ }^{4}$ The pioneering work of Santiago Ramón y $\mathrm{Cajal}^{5}$ demonstrates that, despite attempts to navigate the lesion environment, injured axons fail to regenerate and, ultimately, form dystrophic end bulbs that persist indefinitely in the lesion border. ${ }^{6}$ There has been an extensive amount of research to understand why most axons in the CNS fail to regenerate after injury, especially when compared with axons of the peripheral nervous system (PNS), which have a much greater capacity for regeneration. Two major mechanisms have been proposed to account for this difference in regenerative capability. One major field of study is understanding the intrinsic limitations on the growth potential of the adult CNS neuron, compared with the growth potential of immature neurons in the CNS or adult neurons of the PNS. ${ }^{7}$ The other major area of study is identifying the environmental factors that restrict axon growth potential.
Axonal outgrowth has been studied as a basis for axonal plasticity and regeneration in different modeling paradigms. ${ }^{8} \mathrm{We}$ will survey the axon's response after injury, including axonal dieback and degeneration, then discuss the current understanding of intrinsic pathways affecting CNS axon growth potential, and finally describe the extrinsic factors that have been identified as inhibitors of axonal regeneration. Conversion of axonal growth-promoting interventions into functionality is context dependent (Figure 2), relying on both timing and activity. ${ }^{9}$

\footnotetext{
Supported by the National Institute on Disability, Independent Living, and Rehabilitation Research grant 90SI50200100 (J.M.S.); Wings for Life Spinal Cord Research Foundation (J.M.S.); the Era-Net-NEURON Program of the European Union [SILENCE (\#01EW170A) and SCI-NET (\#01EW1710); J.M.S.]; the W.E. Hunt and C.M. Curtis Endowment (J.M.S.); and the Craig H. Neilsen Foundation (Encino, CA; A.F.). J.M.S. is a Discovery Theme Initiative Scholar (The Ohio State University).

Disclosures: None declared.

This article is part of a review series on neural regeneration and developmental biology in health and disease.
} 


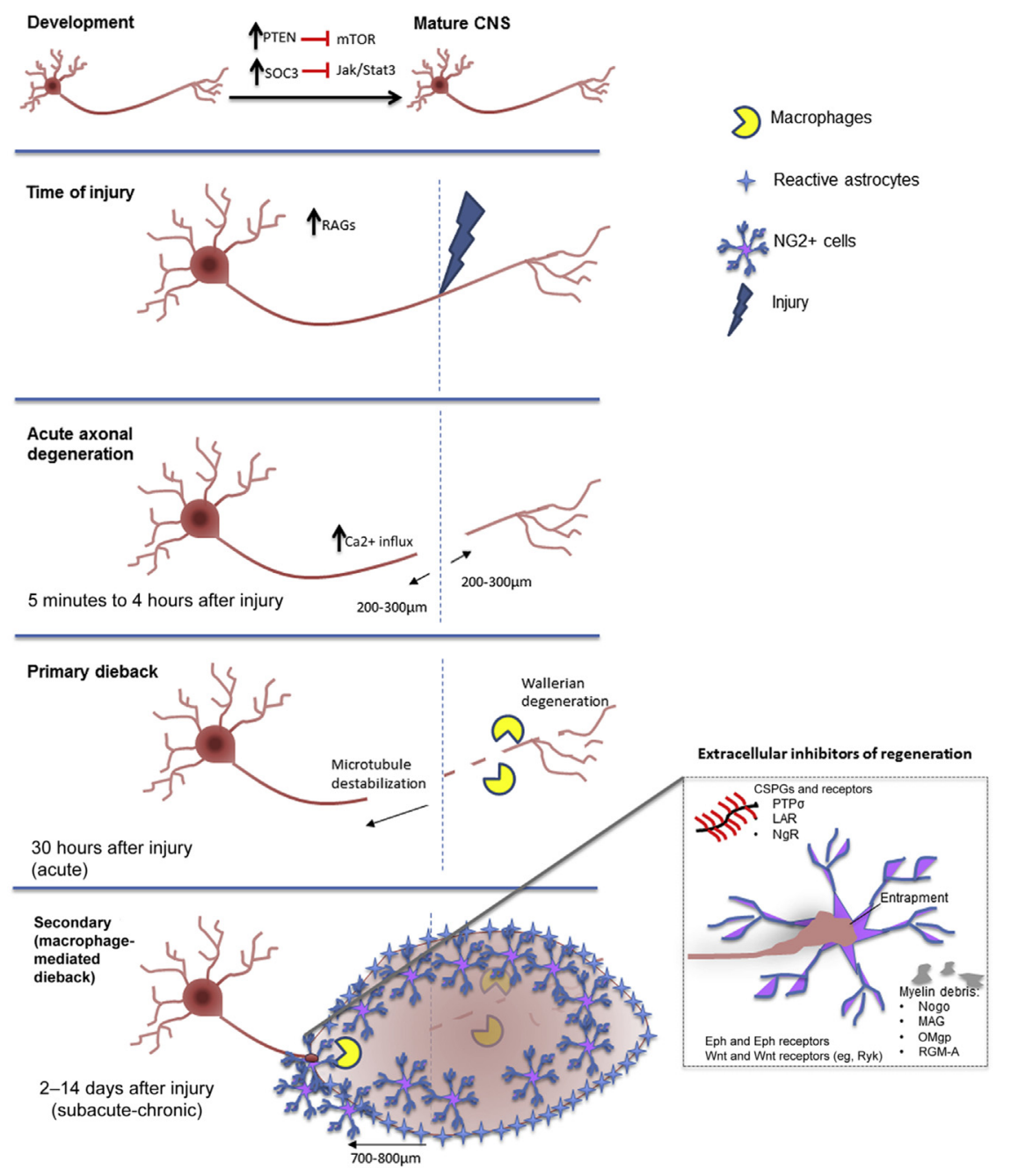

Figure 1 The pattern of axon behavior after injury. During development, axons extend and form an elaborate circuitry that leads to a functional nervous system. As the central nervous system (CNS) matures, signaling that was active during development begins to down-regulate to prevent unwanted growth and plasticity. After injury, regeneration-associated genes (RAGs) are up-regulated to regrow injured fibers to their original targets. The initial response to injury results in calcium influx and an intrinsic retraction from the lesion site within the first 4 hours after injury. During the acute phase after injury, the microtubules within the proximal end of the axon destabilize, whereas the distal end undergoes wallerian degeneration. This destabilization allows the axon to dieback away from the lesion, an intrinsic property of the neuron itself. As the neuron enters the subacute phase of injury (2 to 14 days after injury), macrophages enter the lesion core, contact the axon, and cause the axon to dieback further. The dieback ceases when the injured axon tip reaches the surface of neural-glial $(\mathrm{NG}) 2^{+}$cells in the lesion penumbra, where they become entrapped. This entrapment contributes to regeneration failure. As the glial scar develops during this time, there is an up-regulation of various extracellular molecules that further impede the axon's regeneration potential. CSPG, chondroitin sulfate proteoglycan; Jak, Janus kinase; LAR, leukocyte common antigen related; MAG, myelin-associated glycoprotein; mTOR, mammalian target of rapamycin; $\mathrm{NgR}$, Nogo receptor; 0Mgp, oligodendrocyte-myelin glycoprotein; PTEN, phosphatase and tensin homolog; PTP, protein tyrosine phosphatase; RGM-A, repulsive guidance moleculeA; SOC, suppressor of cytokine signaling 3 .

\section{Intracellular Mechanisms of Regeneration Impairment}

Historically, it has been difficult to distinguish between regenerating fibers and spared fibers using axonal tracing. Postmortem analysis only allows for snapshots of fiber position at certain selected time points, making it difficult to know whether these fibers were spared, degenerating, or regenerating at that moment after injury. In vivo imaging after spinal cord injury (SCI) has vastly improved our understanding of axonal dieback and degeneration. Kerschensteiner and colleagues ${ }^{10}$ used in vivo imaging and a transgenic mouse strain expressing green fluorescent protein under a neuron-specific promotor (thymus cell antigen-1) to visualize a subset of neurons, including those of the dorsal root ganglion. After identifying a particular axon, using blood vessels as a landmark, the authors used a micromanipulator to selectively transect the labeled axon of interest (along with some surrounding axons). The first phenomenon observed was a sudden fragmentation of both the proximal and distal ends of the transected axon, extending approximately 300 $\mu \mathrm{m}$, which the authors termed acute axonal degeneration. Acute axonal degeneration, which happens within the first hour after injury, is followed by axonal retraction. Within 24 to 30 hours after injury, both the proximal and distal ends of the severed fiber dieback symmetrically from the lesion site. By 48 hours after injury, dieback of the proximal end slows, although the authors noted that the end bulb continues to change shape. The proximal end eventually stabilizes approximately $300 \mu \mathrm{m}$ from the lesion site, whereas the distal end begins to undergo wallerian degeneration. Within the first day after injury, many axons mount an initial growth response that ultimately results in a dystrophic growth state. Axonal injury may not only be a yes or no phenomenon. Recent findings report that axonal injury can be reversible $^{11,12}$ and postulate an inherent self-preservation process in contused axons. Further studies using in vivo imaging will help elucidate the mechanisms underlying these abortive attempts at regrowth.

\section{Dystrophic Growth State}

On injury, axons exhibit dystrophic growth cones, first described as sterile clubs by Ramón y Cajal. ${ }^{5}$ The axon no longer extends 


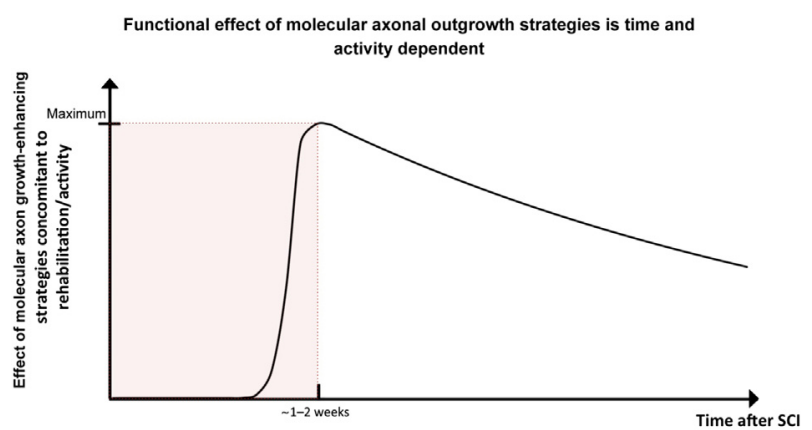

Figure 2 Functional gains of axonal outgrowth are not linearly dependent on time and activity after injury. Interventional studies combining rehabilitative and molecular progrowth strategies during the first 1 to 2 weeks after injury are ineffective in contributing to functional improvement and provide evidence for a critical time window for repair. The early postlesional circuitry during the first 1 to 2 weeks is considered unstable. Destabilizing this further by unlocking sprouting of new fibers does not result in improved voluntary motor function. Instead, sequential designs applying molecular progrowth strategies during the first week, followed by rehabilitative training to stabilize newly formed circuitry starting after 1 to 2 weeks after injury, result in improved outcomes. SCI, spinal cord injury.

lamellopodia, but rather persists in an active, stable state at the edge of the lesion. This dystrophic growth state is at least partly induced by the glial scar that forms around the lesion environment. In a set of microtransplantation studies, adult dorsal root ganglion neurons were able to grow $1 \mathrm{~mm}$ per day within white matter tracts of the CNS for long distances, but their growth halted abruptly as they contacted the glial scar. ${ }^{13}$ There is evidence that these fibers remain responsive, but are unable to progress beyond the lesion core. Evidence from the laboratory of Bradke and colleagues ${ }^{6}$ suggests that these fibers can persist near the lesion core for up to 42 years after injury, addressing the question of whether these fibers continuously dieback over time or stabilize. Further evidence of this active, persistent dystrophic state can be seen using time-lapse microscopy and an in vitro model of the glial scar. The glial scar is characterized by a considerable up-regulation of chondroitin sulfate proteoglycans (CSPGs; described later), which have been shown to inhibit regeneration. Work from the laboratory of Silver and colleagues ${ }^{14}$ demonstrated that as the neurons extend neurites into a gradient of increasing CSPG and decreasing laminin, they become dystrophic. However, they remain active, although they do not make forward movement into the gradient, continually endocytosing membrane and periodically extending and retracting short filopodia. ${ }^{10,15}$

Studies to understand the mechanisms underlying the formation of the dystrophic growth cone demonstrated that, in this state, the growth cone contains disorganized microtubules. ${ }^{16}$ Work by Ertürk and colleagues ${ }^{17}$ furthered these observations when they demonstrated that destabilizing microtubules cause active growth cones to become dystrophic and stabilizing microtubules prevent dystrophic growth cone formation.

The first step to regenerating a severed axon is to reestablish a growth cone at the tip. ${ }^{18}$ In mammals, injured axons of the peripheral nervous system are able to generate a new growth cone within hours after being cut. ${ }^{19,20}$ Conversely, injured CNS axons in mammals retract 200 to $300 \mu \mathrm{m}$ and form retraction bulbs. Only one third of these injured fibers are able to form a new growth cone at the terminal or at a node of Ranvier. ${ }^{10,17}$ The first step to generating a new growth cone comes from the disruption of the membrane, resulting in a calcium influx. This passive influx of calcium is further propagated by the activation of voltage-gated ion channels, resulting in an elevated intracellular calcium concentration. This calcium influx causes microtubule and actin depolymerization retrogradely down the axon, ${ }^{21,22}$ as well as activation of calpains. The proteolytic activity of calpains peaks rapidly after axotomy, within 10 to 30 minutes, and then returns to baseline by 60 minutes. ${ }^{23}$ This brief calpain activation is responsible for restructuring the cytoskeleton of the axotomized tip. ${ }^{22-24}$ The calcium influx is also necessary for resealing the membrane, as demonstrated by the findings that in low calcium conditions $(<100 \mu \mathrm{mol} / \mathrm{L})$, membrane sealing does not occur and axon degeneration results. ${ }^{25,26}$ The neuron must act quickly to repair the ruptured membrane to restore ion homeostasis. This process happens within minutes to hours after axotomy. Calcium-mediated membrane collapse seals off the severed end of the injured axon, which allows for calcium removal mechanisms to set in to restore ion homeostasis. Once the membrane has been sealed, a new growth cone can form, beginning with microtubule and actin repolymerization.

\section{Axonal Dieback}

Axons exhibit different responses to inhibition and injury. When the axon tip is unable to make forward progress, but also does not retract, the axon is said to be in a state of growth cone dystrophy, in which the axon tip persists where it is, turning over membrane and forming vesicles. ${ }^{14}$ Growth cone collapse involves a short and temporary retraction from the growth cone's initial position, losing lamellapodia and filopodia. However, the growth cone will usually begin to extend again. In the case of axonal retraction or dieback, the axon tip regresses away from the lesion over a much greater distance than growth cone collapse, eventually stabilizing in proximity to the lesion border. ${ }^{27,28}$

Axonal dieback was first described by Ramón y $\mathrm{Cajal}^{5}$ when he observed severed axon tips retracting away from the site of injury over time, which he believed was intrinsic to the neurons themselves. Evidence now shows that two phases of axonal dieback exist. The initial phase of axonal dieback appears to be an intrinsic property of neurons themselves, as demonstrated using in vivo imaging. Ascending sensory axons retract several hundred micrometers within hours after injury before they stabilize for several days. ${ }^{10}$ The secondary phase of axonal dieback correlates with the infiltration of activated macrophages and appears to be contact dependent ${ }^{15,28,29}$ (Figure 1).

\section{Inflammation in the CNS: Macrophage-Mediated Axonal Dieback}

Neuroinflammation plays a major role after SCI, but its exact function in regeneration failure remains controversial. 
Immediately after injury, the blood-brain barrier breaks down. ${ }^{30}$ Resident CNS cells up-regulate proinflammatory cytokines and chemokines within the first hour after injury. ${ }^{31}$ Neutrophils infiltrate the lesion site within 3 hours, phagocytose debris, and remain elevated for 3 days. ${ }^{32}$ Resting microglia, which normally survey the CNS for insult, become activated within 24 hours after injury, resulting in changes in their morphology and the release of chemokines and cytokines. ${ }^{30,33} \mathrm{CD}^{+} 8^{+}$cells increase dramatically after injury within the first 7 days, then slowly increase until 2 to 4 weeks after injury. ${ }^{28,30}$ CD68 labels both activated microglia and infiltrating macrophages, so it is difficult to distinguish between these two cell types based on this marker alone. Along a similar time frame, T lymphocytes increase at the site of injury, although not to the extent of macrophages. ${ }^{34}$

Although macrophages phagocytose debris ${ }^{35}$ and can secrete neurotrophic factors, ${ }^{36,37}$ previous work from the laboratory of Silver and colleagues ${ }^{28,29}$ suggests these cells induce axonal dieback through direct contact with the dystrophic endings of axons. After SCI, long-distance retraction of injured axons coincides with the infiltration of activated macrophages. Depletion of infiltrating macrophages using clodronate liposomes significantly reduced axonal dieback, but did not enhance regeneration. ${ }^{28}$ The authors found that the growth state of the axon was important to facilitate this axonal retraction, because only dystrophic axons were susceptible to macrophage-mediated dieback in vitro. Inhibiting matrix metallopepetidase-9, degrading proteoglycans at the site of injury, and enhancing the growth potential of injured axons through the use of a conditioning lesion were all sufficient to block this macrophage-mediated dieback. ${ }^{29}$ Using a radiation chimera model and high-resolution in vivo imaging, Evans and colleagues ${ }^{15}$ were able to distinguish between the actions of resident CNS microglia and infiltrating blood-derived macrophages and demonstrated that blood-derived macrophages alone are responsible for this secondary axonal dieback after SCI. A milestone contribution by Kigerl and colleagues $^{38}$ was that the effect of microglia/macrophages being neurotoxic or growth promoting was largely dependent on their polarization toward different subsets.

\section{Intrinsic Growth Capacity for Injured CNS Neurons}

After dieback, injured neurons of the adult CNS are only capable of modest sprouting and minimal regeneration, even with neutralizing various inhibitory components of the extracellular environment, suggesting their intrinsic growth capacity is reduced over time. To initiate regeneration, the injured axon must transmit an injury signal back to the soma, where the neuron begins transcribing various regeneration-associated genes. ${ }^{39}$ Axotomy leads to a rapid influx of ions, increasing the intracellular calcium concentration, which can act as an injury signal. ${ }^{40}$ Injury also induces cytokine expression that can act as a signal for downstream signaling. In particular, the family of cytokines that signal through the glycoprotein 130 receptor has been implicated as an injury signal in the periphery, resulting in signal transduction through the Janus kinase/STAT pathway. These cytokines, including ciliary neurotrophic factor and IL-6, are expressed after axotomy and promote regeneration in the periphery. ${ }^{41-43}$ This work has been expanded to spinal cord injury. IL-6 has been implicated in proinflammatory signaling, with both positive ${ }^{44}$ and negative $\mathrm{e}^{45}$ effects on regeneration reported. Leukemia inhibitory factor has been implicated in oligodendrocyte preservation, ${ }^{46}$ and when leukemia inhibitory factor was delivered directly into the dorsally hemisected spinal cord, it was able to enhance the growth of injured corticospinal axons. ${ }^{47}$ Ciliary neurotrophic factor has also been shown to mediate stroke-induced neurogenesis, ${ }^{48}$ further suggesting that this cytokine family can have an important role in regeneration signaling.

To promote regeneration, efforts have been made to enhance the intrinsic growth capacity of adult CNS neurons. One method that has augmented the regenerative ability of neurons in animal models is the use of a conditioning lesion. Injuring the peripheral branch of a sensory neuron in the sciatic nerve enhances the ability of the central process to regenerate beyond a central lesion. ${ }^{49}$ This effect can be achieved even if the conditioning lesion is performed immediately after the central injury. ${ }^{50,51}$ Although the exact mechanism of how distal conditioning stimulates intrinsic growth of central processes remains under investigation, this method to enhance growth has elucidated several regeneration-associated transcription factors, including c-Jun, CCAAT/enhancer binding proteins, cAMP responsive element binding, STAT3, activating transcription factor 3, SRYbox 1, and Smad1. ${ }^{39}$ A study with dorsal root ganglion neurons found that STAT3 activation is necessary to produce the conditioning lesion effect. ${ }^{52}$ There is some work to suggest that the conditioning lesion effect is partly achieved through the glycoprotein 130 signaling described above. ${ }^{53,54}$ Several other methods have been used to try to replicate this conditioning effect without the negative consequences of harming peripheral nerves. For instance, inducing inflammation within the dorsal root ganglion (DRG) $)^{55}$ or the vitreous of the eye $\mathrm{e}^{56}$ has also been shown to enhance intrinsic growth of these neurons. Furthermore, adding $\mathrm{cAMP}^{57}$ or electrically stimulating the intact sciatic nerve ${ }^{58}$ has also been shown to replicate the conditioning lesion effect.

In a series of pioneering studies from Zhigang He's laboratory in the late 2000s, phosphatase and tensin homolog, a negative regulator of the mammalian target of rapamycin pathway, emerged as a major determinant of CNS axon regeneration. One of the most notable studies on enhancing intrinsic growth capacity came from Park et al, ${ }^{59}$ which demonstrated that a targeted deletion of phosphatase and tensin homolog in adult mice allowed robust regeneration after optic nerve injury. Using intravitreal injections of adeno-associated viruses expressing Cre, the authors managed to express Cre in $>90 \%$ of retinal ganglion cells to conditionally knock down expression of Pten, resulting in remarkable regeneration of these optic nerve fibers through cholera toxin B tracings. This pathway was shown later to be important for regeneration of adult corticospinal neurons as 
well, in which a conditional phosphatase and tensin homolog deletion enabled unprecedented regeneration beyond the lesion site. ${ }^{60}$ The phosphatase and tensin homolog/mammalian target of rapamycin pathway is required for tumor suppression and is thought to be turned on after development to stop unwanted growth and sprouting within the CNS. Therefore, despite the promising results in achieving regeneration, caution should be exercised before moving these findings into therapeutics. A recent study examined the long-term effects of deleting Pten in the sensorimotor cortex of neonatal mice. ${ }^{61}$ After a spinal cord injury in these mice as adults, the authors reported robust regeneration of corticospinal tract (CST) axons, similar to what was observed in earlier studies. ${ }^{60}$ However, the purpose of this study was to assess the long-term consequences of this targeted deletion. The authors observed larger layer $\mathrm{V}$ neurons in mice lacking Pten than in those that maintained Pten expression, but they did not observe significant differences in open field activity, RotaRod (TSE Systems, Chesterfield, MO) motor performance, tumor formation, or other neuropathology, suggesting this early deletion of Pten caused little neuropathology in adult mice. Better understanding of these molecules and pathways will provide new avenues for regenerative research.

\section{Extracellular Mechanisms of Regeneration Failure}

Enhancing the intrinsic growth capacity of CNS neurons is a major obstacle in achieving regeneration. Another impediment to growing CNS axons is the inhibitory extrinsic factors that exist in and around the lesion environment. By using peripheral nerve grafts to connect the medulla to the spinal cord, David and Aguayo ${ }^{62}$ demonstrated that central axons from both levels were able to regrow $30 \mathrm{~mm}$ through this peripheral environment, illustrating the inhibitory nature of the CNS environment. Extensive research has been performed to understand the differences between the CNS and PNS environment that allow axons to regrow in the periphery but not in the CNS. CSPGs and factors associated with CNS myelin are among the leading groups of molecules studied for their inhibitory properties, but other factors are up-regulated after injury as well and contribute to regeneration failure. Together, these molecules are found in and around the glial scar, generating a hostile environment for axon growth.

\section{Formation of the Glial Scar}

Immediately after SCI, extensive inflammation occurs at the site of injury, leading to cavitation that extends the primary insult. Over time, reactive astrocytes surround this lesioned area to form what is known as the glial scar. This scar is made up of two distinct components: the lesion core that is composed of a variety of cell types, including infiltrating macrophages, neural-glial (NG) $2^{+}$cells, fibroblasts, and pericytes; and the penumbra, which is made up of hypertrophic astrocytes that surround the lesion core and wall off the injured area from surrounding healthy tissue. ${ }^{63}$

The glial scar is a complex environment of extracellular matrix and cell types that intermingle to form a dense structure. This structure serves to protect neighboring tissue, but also acts as a major impediment to regenerating axons. Using a nitrocellulose support to remove an intact glial scar from an adult rat after CNS trauma, Rudge and Silver ${ }^{64}$ demonstrated, in vitro, that this glial scar explant was inhibitory to purified rat hippocampal neurons. Further work in vivo showed that microtransplanted adult DRG neurons were able to grow long distances through white and gray matter of the CNS, only halting growth abruptly on entering the lesion site containing upregulated extracellular matrix molecules, such as CSPGs. ${ }^{13}$ This work demonstrated, for the first time, that the glial scar inhibits regeneration of adult CNS neurons. Since then, extensive research has been performed to try to overcome the inhibitory nature of the glial scar, specifically CSPGs (described CSPGs and Their Receptors). However, recent work from Michael Sofroniew's laboratory is challenging the dogma that the glial scar impedes functional recovery. ${ }^{65}$ Beginning with a study in 2004, Faulkner et al ${ }^{65}$ used mice expressing herpes simplex virus thymidine kinase under a glial fibrillary acidic protein promotor to ablate reactive astrocytes in the vicinity of the lesion on treatment with the antiviral agent ganciclovir. The authors report widespread tissue disruption, enhanced cellular degeneration, demyelination, greater cell death of both neurons and oligodendrocytes, and motor deficits when astrocytes were ablated after small stab injuries or moderate crush injuries, suggesting astrocytes are crucial to protect surrounding tissue from the spread of injury. Together, these studies demonstrate the importance of the glial scar in containing the inflammatory processes to the site of injury and protecting surrounding healthy tissue. The early immature scar may be even implicated in sprouting responses because immature astrocytes are, for example, known for exerting growth-promoting capacities. ${ }^{66}$

\section{CSPGs and Their Receptors}

One major component of the glial scar is a family of extracellular matrix proteins known as CSPGs, which consist of a protein backbone and glycosaminoglycan (GAG) chains. The varying number, length, and sulfation of GAG chains attached to the core protein provide each CSPG with its unique properties. ${ }^{63}$ CSPGs are present throughout the developing and adult CNS; however, their expression is dramatically increased after injury, in the vicinity of the disrupted blood-brain barrier. ${ }^{67}$ Reactive astrocytes are responsible for producing and secreting many of the CSPGs after injury, and their up-regulated expression persists for months. ${ }^{68,69}$ These molecules have been shown to inhibit neurons in development, ${ }^{70}$ in culture, ${ }^{70}$ and after injury. ${ }^{63}$ Because neurons extend processes into an increasing gradient of CSPG, their growth halts and their growth cones become dystrophic. ${ }^{14}$ CSPGs have also been implicated in the formation of perineuronal nets, which prevent aberrant synaptic plasticity in uninjured adult animals. ${ }^{71}$ Much of 
their inhibition is thought to be mediated through their GAG chains, because removing these structures leads to regeneration and functional recovery after SCI. ${ }^{72}$ Recent studies have implicated CSPGs in remyelination deficits as well, further contributing to regeneration inhibition. CSPGs have been shown to inhibit the process outgrowth and differentiation of oligodendrocyte progenitor cells in vitro. ${ }^{73}$ By inhibiting CSPG synthesis, a recent study was able to accelerate remyelination in a focal demyelination mouse model. ${ }^{74}$ Therefore, by direct interaction with injured axons or through indirect effects on myelination, CSPGs have an established role in regeneration failure.

It was thought that CSPGs inhibited neurons through nonspecific mechanisms. Many believed the negatively charged boundary formed by CSPGs repelled neurons ${ }^{75}$ or that neurons were inhibited because of substrate occlusion ${ }^{76}$ caused by CSPGs. However, the recent discovery of several CSPG receptors has shifted the thought about how CSPGs inhibit neurite outgrowth. The leukocyte common antigenrelated family of receptor tyrosine phoshatases has been identified to specifically bind CSPGs and mediate inhibition. Receptor protein tyrosine phosphatase $\sigma^{77}$ was identified first, followed by fellow leukocyte common antigen-related family member leukocyte common antigen related. ${ }^{78}$ Protein tyrosine phosphatase $\delta$ is also assumed to be a receptor, because of its high sequence homology with leukocyte common antigen related and protein tyrosine phosphatase $\sigma$, but this has yet to be described. These members all contain a canonical GAG binding motif composed of a cluster of lysine residues. ${ }^{79}$ Nogo receptor $(\mathrm{NgR}) 1$ and $\mathrm{NgR} 3$ have also been identified as CSPG receptors. ${ }^{80}$ Although knocking out either NgR1 or NgR3 individually was not sufficient to overcome CSPG-mediated inhibition, their combined loss allowed for significant regrowth of severed retinal ganglion cells. This study provides a link between two different classes of inhibitory molecules, those associated with myelin and with CSPGs.

Many different signaling pathways have been implicated in CSPG-mediated inhibition. When neurons contact CSPGs, the $\rho / \rho$-associated protein kinase signaling pathway is activated, and blocking this signaling attenuates inhibition. ${ }^{81}$ Protein kinase $\mathrm{C}$ has been implicated downstream of the $\rho$ pathway, because inhibiting protein kinase $\mathrm{C}$ blocks signaling from $\rho$ activation and promotes dorsal column regeneration. ${ }^{82}$ In addition, CSPG-mediated calcium influx activates the epidermal growth factor receptor and blocking this kinase function blocks inhibition, suggesting epidermal growth factor receptor also mediates CSPG inhibition. ${ }^{83}$

Chondroitinase ABC (ch'ase) is an enzyme that selectively cleaves GAG chains from the protein core of CSPGs. Many studies have used this enzyme to reduce or eliminate inhibition both in vitro and in vivo, suggesting much of the inhibitory properties of CSPGs are attributable to their GAG chains. ${ }^{67}$ Administering ch'ase intrathecally promoted regeneration of sensory and CST axons after a dorsal column lesion, ${ }^{72}$ restoring postsynaptic activity below the lesion and promoting functional recovery of locomotor and proprioceptive behaviors. Ch'ase has also been shown to promote regeneration of axons in the Clarke nucleus projections and the rubrospinal tract. ${ }^{84,85} \mathrm{Ch}$ 'ase has also been used in many combinatorial strategies to improve regeneration, ${ }^{86-89}$ demonstrating the inhibitory properties of these molecules and the complexity of restoring regeneration.

\section{Entrapment}

Another reason for regeneration failure has been discovered recently. First described in 1985, Carlstedt ${ }^{90}$ observed that fibers regrowing through the dorsal root were able to elongate until they reached the dorsal root entry zone, the interface between the PNS and CNS, where some fibers began to form synaptoid nerve terminals with a glial cell population. Further studies demonstrated that an active signaling pathway was responsible for this abrupt stopping behavior just as the root enters the spinal cord, ${ }^{91}$ which was termed the physiological stop pathway. In both studies, the authors believed the fibers were forming stable connections with reactive astrocytes. However, $\mathrm{NG2}^{+}$cells were not yet discovered. ${ }^{92}$ In vivo imaging has been used to visualize this synaptic-like stabilization at the dorsal root entry zone. ${ }^{93}$ Later studies found similar findings in the spinal cord, where injured fibers in the spinal cord cease retracting in an area of $\mathrm{NG}^{+}$cells. $^{94,95}$ Herein, neurons become entrapped on the $\mathrm{NG}^{+}$cell surface, where they begin to form synaptic-like connections with this glial cell population. ${ }^{27}$ This cell-cell interaction is facilitated by the laminin and NG2 molecules on the $\mathrm{NG}^{+}$cell surface and the receptors on the neurons. Although ch'ase treatment can release neurons from the $\mathrm{NG}^{+}$cell surface acutely in in vitro cultures, this interaction becomes difficult to break by 5 days in vitro. This emerging mechanism of regeneration failure begins to address the conflicting findings that, although CSPGs are known to be inhibitory, dystrophic axons tend to associate in an area of high CSPG expression chronically, causing us to rethink our understanding of how CSPGs inhibit growth. ${ }^{96}$

\section{Myelin Components and NOGO}

The components of CNS myelin differ from those of PNS myelin and have been implicated in neurite outgrowth inhibition in vitro. ${ }^{97}$ Although myelin-associated glycoprotein, ${ }^{98,99}$ oligodendrocyte-myelin glycoprotein, ${ }^{100,101}$ and $\mathrm{Nogo}^{102}$ are all present in CNS myelin and inhibit neurite outgrowth in vitro, only Nogo has been shown to inhibit regeneration in vivo. ${ }^{103}$ However, the inhibitory properties of Nogo have been debated. ${ }^{104}$ Knocking out all three receptors for Nogo, either singly or in combination, did not allow for meaningful enhanced regeneration. ${ }^{105,106}$ These diverging results are largely attributable to differences in methodology, as myelinassociated inhibitors affect axonal sprouting rather than axonal regeneration. ${ }^{107}$ It appears that these inhibitors operate with modulators of intrinsic growth state in a sequential manner. Once the intrinsic state is elevated, extrinsic growth modulators including myelin-associated inhibitors are likely to serve as a subsequent barrier to regeneration. ${ }^{107}$ 


\section{Other Inhibitors of Axonal Regeneration}

The extracellular environment contains other inhibitors along with CSPGs and components of CNS myelin. The repulsive guidance molecule-A, Ephrin and its receptors, semaphorins (Semas), the Wnt receptor Ryk tenascin-R, and slits have all been implicated in inhibiting regeneration.

Repulsive guidance molecule-A is repulsive for axon growth during development ${ }^{108}$ on binding to its receptor neogenin. ${ }^{109}$ Repulsive guidance molecule- $\mathrm{A}$ is expressed by oligodendrocytes and reactive astrocytes after SCI and localized to CNS myelin and the developing glial scar. ${ }^{110}$ Repulsive guidance molecule-A inhibits mammalian CNS neurite outgrowth by a mechanism dependent on the activation of the $\rho \mathrm{A}-\rho$ kinase pathway. ${ }^{108}$

Tenascin- $\mathrm{R}$ is believed to play a role in the formation of the perineuronal net, which functions in development and limits plasticity after injury. Tenascin-R increases after SCI. Tenascin- $\mathrm{R}$-deficient mice have enhanced regeneration, which appears to be mediated through rearrangement of the perineuronal net rather than acting on the neuron for regrowth directly. ${ }^{111}$ There is also some evidence suggesting slits are up-regulated after cortical injury, potentially affecting regeneration. ${ }^{112}$

Ephrin and Eph receptors have well-established roles in development, functioning in axon guidance and patterning. These molecules are also up-regulated after CNS injury, leading to speculation that these molecules play a role in regeneration failure. In particular, Ephrin-B expression on astrocytes and $\mathrm{EphB}$ expression on fibroblasts have been shown to segregate these cell types at the lesion site, aiding in formation of the glial scar and reestablishment of the blood-brain barrier. ${ }^{113}$ Beyond a possible role in scar formation, the interaction of ephrinB3 on postnatal mouse oligodendrocytes with EphA4 on cortical neurons inhibits these neurons, possibly playing a role in regeneration failure. ${ }^{114}$ Furthermore, EphA4 accumulates in CST axons after SCI, which may allow these axons to respond to ephrinB3 in myelin or ephrinB2 in scar tissue. Blocking this signaling with peptide enhanced sprouting, but not regeneration, of these axons. ${ }^{115}$

Semas have also been studied as inhibitory and repulsive guidance cues. When applied in vitro, Sema3A caused growth cone collapse of adult DRG neurons. ${ }^{116}$ Sema3A is also present within the lesion environment after SCI, where preconditioned adult DRG axons cease growing. ${ }^{117}$ Sema3A appears to inhibit in a CSPG-dependent manner, because studies blocking the interaction of Sema3s and CSPGs in vitro reduce Sema3A inhibition. ${ }^{117}$ Some studies with a small molecule (SM-216289), which blocks the binding of Sema3A with the neuropilin-1/plexinA receptor complex, reduced DRG inhibition in vitro and enhanced regeneration after olfactory nerve axotomy in rat. ${ }^{118}$ It also enhanced regeneration of serotonergic axons, but not CST or ascending sensory axons, after SCI. ${ }^{119}$ In addition to functioning as a guidance molecule, Sema3s function in vascular remodeling, ${ }^{120}$ the immune system, ${ }^{121}$ and cell death, ${ }^{122-124}$ which may all affect regeneration after SCI.

Finally, the Wnt family of developmental guidance molecules has been implicated in SCI, in particular with CST axons. Ascending and descending axons respond differently to Wnt stimulation, which is likely mediated through their different expression of receptors. Recently, the Wnt receptor Ryk has been identified as a negative determinant blocking neurite outgrowth, resulting in plasticity in lesion-remote areas. ${ }^{125}$

The observation by Aguayo and colleagues ${ }^{126}$ in the late 1970s/early 1980s was followed by an intense and successful search identifying growing numbers of molecules implicated in modulating axonal growth. Pertinent questions remain regarding the redundancy and functional hierarchy elicited by the increasingly large number of molecules.

\section{Conclusion}

Major progress has been made in understanding what impedes regeneration after SCI. A variety of different strategies have been used to achieve regrowth beyond the lesion center, and in some cases, this regrowth has been significant for a large, albeit still limited, number of fibers. Combinatorial strategies have been more successful in achieving this goal. However, as the field of regeneration makes great strides in enhancing the growth capacity of these injured axons, we must now think even more about how to reintegrate these growing fibers back into the circuitry that was established during development to restore proper function.

\section{References}

1. Monti Graziadei GA, Karlan MS, Bernstein JJ, Graziadei PP: Reinnervation of the olfactory bulb after section of the olfactory nerve in monkey (Saimiri sciureus). Brain Res 1980, 189:343-354

2. Morrison EE, Costanzo RM: Regeneration of olfactory sensory neurons and reconnection in the aging hamster central nervous system. Neurosci Lett 1995, 198:213-217

3. Chauvet N, Prieto M, Alonso G: Tanycytes present in the adult rat mediobasal hypothalamus support the regeneration of monoaminergic axons. Exp Neurol 1998, 151:1-13

4. Hawthorne AL, Hu H, Kundu B, Steinmetz MP, Wylie CJ, Deneris ES, Silver J: The unusual response of serotonergic neurons after CNS injury: lack of axonal dieback and enhanced sprouting within the inhibitory environment of the glial scar. J Neurosci 2011, 31:5605-5616

5. Ramón y Cajal S: Degeneration and Regeneration of the Nervous System. London, Oxford University Press, 1928

6. Ruschel J, Hellal F, Flynn KC, Dupraz S, Elliott DA, Tedeschi A, Bates M, Sliwinski C, Brook G, Dobrindt K, Peitz M, Brüstle O, Norenberg MD, Blesch A, Weidner N, Bunge MB, Bixby JL, Bradke F: Axonal regeneration: systemic administration of epothilone B promotes axon regeneration after spinal cord injury. Science 2015, 348:347-352

7. He Z, Jin Y: Intrinsic control of axon regeneration. Neuron 2016, 90: $437-451$

8. Tuszynski MH, Steward O: Concepts and methods for the study of axonal regeneration in the CNS. Neuron 2012, 74:777-791 
9. Chen K, Marsh BC, Cowan M, Al'Joboori YD, Gigout S, Smith CC, Messenger N, Gamper N, Schwab ME, Ichiyama RM: Sequential therapy of anti-Nogo-A antibody treatment and treadmill training leads to cumulative improvements after spinal cord injury in rats. Exp Neurol 2017, 292:135-144

10. Kerschensteiner M, Schwab ME, Lichtman JW, Misgeld T: In vivo imaging of axonal degeneration and regeneration in the injured spinal cord. Nat Med 2005, 11:572-577

11. Williams PR, Marincu B-N, Sorbara CD, Mahler CF, Schumacher AM, Griesbeck O, Kerschensteiner M, Misgeld T: A recoverable state of axon injury persists for hours after spinal cord contusion in vivo. Nat Commun 2014, 5:5683

12. Aboul-Enein F, Weiser P, Höftberger R, Lassmann H, Bradl M: Transient axonal injury in the absence of demyelination: a correlate of clinical disease in acute experimental autoimmune encephalomyelitis. Acta Neuropathol 2006, 111:539-547

13. Davies SJ, Fitch MT, Memberg SP, Hall AK, Raisman G, Silver J: Regeneration of adult axons in white matter tracts of the central nervous system. Nature 1997, 390:680-683

14. Tom VJ, Steinmetz MP, Miller JH, Doller CM, Silver J: Studies on the development and behavior of the dystrophic growth cone, the hallmark of regeneration failure, in an in vitro model of the glial scar and after spinal cord injury. J Neurosci 2004, 24:6531-6539

15. Evans TA, Barkauskas DS, Myers JT, Hare EG, You JQ, Ransohoff RM, Huang AY, Silver J: High-resolution intravital imaging reveals that blood-derived macrophages but not resident microglia facilitate secondary axonal dieback in traumatic spinal cord injury. Exp Neurol 2014, 254:109-120

16. Li Y, Raisman G: Sprouts from cut corticospinal axons persist in the presence of astrocytic scarring in long-term lesions of the adult rat spinal cord. Exp Neurol 1995, 134:102-111

17. Ertürk A, Hellal F, Enes J, Bradke F: Disorganized microtubules underlie the formation of retraction bulbs and the failure of axonal regeneration. J Neurosci 2007, 27:9169-9180

18. Bradke F, Fawcett JW, Spira ME: Assembly of a new growth cone after axotomy: the precursor to axon regeneration. Nat Rev Neurosci 2012, 13:183-193

19. Morris JH, Hudson AR, Weddell G: A study of degeneration and regeneration in the divided rat sciatic nerve based on electron microscopy, II: the development of the "regenerating unit." Z Zellforsch Mikrosk Anat 1972, 124:103-130

20. Friede RL, Bischhausen R: The fine structure of stumps of transected nerve fibers in subserial sections. J Neurol Sci 1980, 44:181-203

21. Sahly I, Khoutorsky A, Erez H, Prager-Khoutorsky M, Spira ME: Online confocal imaging of the events leading to structural dedifferentiation of an axonal segment into a growth cone after axotomy. J Comp Neurol 2006, 494:705-720

22. Spira ME, Oren R, Dormann A, Gitler D: Critical calpain-dependent ultrastructural alterations underlie the transformation of an axonal segment into a growth cone after axotomy of cultured Aplysia neurons. J Comp Neurol 2003, 457:293-312

23. Gitler D, Spira ME: Real time imaging of calcium-induced localized proteolytic activity after axotomy and its relation to growth cone formation. Neuron 1998, 20:1123-1135

24. Gitler D, Spira ME: Short window of opportunity for calpain induced growth cone formation after axotomy of Aplysia neurons. J Neurobiol 2002, 52:267-279

25. Spira ME, Benbassat D, Dormann A: Resealing of the proximal and distal cut ends of transected axons: electrophysiological and ultrastructural analysis. J Neurobiol 1993, 24:300-316

26. Yawo H, Kuno M: How a nerve fiber repairs its cut end: involvement of phospholipase A2. Science 1983, 222:1351-1353

27. Filous AR, Tran A, Howell CJ, Busch SA, Evans TA, Stallcup WB, Kang SH, Bergles DE, Lee S, Levine JM, Silver J: Entrapment via synaptic-like connections between NG2 proteoglycan + cells and dystrophic axons in the lesion plays a role in regeneration failure after spinal cord injury. J Neurosci 2014, 34:16369-16384
28. Horn KP, Busch SA, Hawthorne AL, van Rooijen N, Silver J: Another barrier to regeneration in the CNS: activated macrophages induce extensive retraction of dystrophic axons through direct physical interactions. J Neurosci 2008, 28:9330-9341

29. Busch SA, Horn KP, Silver DJ, Silver J: Overcoming macrophagemediated axonal dieback following CNS injury. J Neurosci 2009, 29:9967-9976

30. Hausmann ON: Post-traumatic inflammation following spinal cord injury. Spinal Cord 2003, 41:369-378

31. Pan JZ, Ni L, Sodhi A, Aguanno A, Young W, Hart RP: Cytokine activity contributes to induction of inflammatory cytokine mRNAs in spinal cord following contusion. J Neurosci Res 2002, 68:315-322

32. Chatzipanteli K, Yanagawa Y, Marcillo AE, Kraydieh S, Yezierski RP, Dietrich WD: Posttraumatic hypothermia reduces polymorphonuclear leukocyte accumulation following spinal cord injury in rats. J Neurotrauma 2000, 17:321-332

33. Davalos D, Grutzendler J, Yang G, Kim JV, Zuo Y, Jung S, Littman DR, Dustin ML, Gan W-B: ATP mediates rapid microglial response to local brain injury in vivo. Nat Neurosci 2005, 8:752-758

34. Popovich PG: Immunological regulation of neuronal degeneration and regeneration in the injured spinal cord. Prog Brain Res 2000, 128:43-58

35. Guth L, Zhang Z, Steward O: The unique histopathological responses of the injured spinal cord: implications for neuroprotective therapy. Ann N Y Acad Sci 1999, 890:366-384

36. Donnelly DJ, Popovich PG: Inflammation and its role in neuroprotection, axonal regeneration and functional recovery after spinal cord injury. Exp Neurol 2008, 209:378-388

37. Profyris C, Cheema SS, Zang D, Azari MF, Boyle K, Petratos S: Degenerative and regenerative mechanisms governing spinal cord injury. Neurobiol Dis 2004, 15:415-436

38. Kigerl KA, Gensel JC, Ankeny DP, Alexander JK, Donnelly DJ, Popovich PG: Identification of two distinct macrophage subsets with divergent effects causing either neurotoxicity or regeneration in the injured mouse spinal cord. J Neurosci 2009, 29:13435-13444

39. Sun F, He Z: Neuronal intrinsic barriers for axon regeneration in the adult CNS. Curr Opin Neurobiol 2010, 20:510-518

40. Mandolesi G, Madeddu F, Bozzi Y, Maffei L, Ratto GM: Acute physiological response of mammalian central neurons to axotomy: ionic regulation and electrical activity. FASEB J 2004, 18: 1934-1936

41. Cafferty WB, Gardiner NJ, Gavazzi I, Powell J, McMahon SB, Heath JK, Munson J, Cohen J, Thompson SW: Leukemia inhibitory factor determines the growth status of injured adult sensory neurons. J Neurosci 2001, 21:7161-7170

42. Cao Z, Gao Y, Bryson JB, Hou J, Chaudhry N, Siddiq M, Martinez J, Spencer T, Carmel J, Hart RB, Filbin MT: The cytokine interleukin-6 is sufficient but not necessary to mimic the peripheral conditioning lesion effect on axonal growth. J Neurosci 2006, 26 : $5565-5573$

43. Leibinger M, Müller A, Andreadaki A, Hauk TG, Kirsch M, Fischer D: Neuroprotective and axon growth-promoting effects following inflammatory stimulation on mature retinal ganglion cells in mice depend on ciliary neurotrophic factor and leukemia inhibitory factor. J Neurosci 2009, 29:14334-14341

44. Okada S, Nakamura M, Mikami Y, Shimazaki T, Mihara M, Ohsugi Y, Iwamoto Y, Yoshizaki K, Kishimoto T, Toyama Y, Okano H: Blockade of interleukin-6 receptor suppresses reactive astrogliosis and ameliorates functional recovery in experimental spinal cord injury. J Neurosci Res 2004, 76:265-276

45. Lacroix S, Chang L, Rose-John S, Tuszynski MH: Delivery of hyperinterleukin-6 to the injured spinal cord increases neutrophil and macrophage infiltration and inhibits axonal growth. J Comp Neurol 2002, 454:213-228

46. Kerr BJ, Patterson PH: Leukemia inhibitory factor promotes oligodendrocyte survival after spinal cord injury. Glia 2005, 51:73-79

47. Blesch A, Uy HS, Grill RJ, Cheng JG, Patterson PH, Tuszynski MH: Leukemia inhibitory factor augments neurotrophin expression and 
corticospinal axon growth after adult CNS injury. J Neurosci 1999, 19:3556-3566

48. Kang SS, Keasey MP, Arnold SA, Reid R, Geralds J, Hagg T: Endogenous CNTF mediates stroke-induced adult CNS neurogenesis in mice. Neurobiol Dis 2013, 49:68-78

49. McQuarrie IG, Grafstein B: Axon outgrowth enhanced by a previous nerve injury. Arch Neurol 1973, 29:53-55

50. Neumann S, Woolf CJ: Regeneration of dorsal column fibers into and beyond the lesion site following adult spinal cord injury. Neuron 1999, 23:83-91

51. Neumann S, Skinner K, Basbaum AI: Sustaining intrinsic growth capacity of adult neurons promotes spinal cord regeneration. Proc Natl Acad Sci U S A 2005, 102:16848-16852

52. Qiu J, Cafferty WBJ, McMahon SB, Thompson SWN: Conditioning injury-induced spinal axon regeneration requires signal transducer and activator of transcription 3 activation. J Neurosci 2005, 25: $1645-1653$

53. Hyatt Sachs H, Rohrer H, Zigmond RE: The conditioning lesion effect on sympathetic neurite outgrowth is dependent on gp130 cytokines. Exp Neurol 2010, 223:516-522

54. Zigmond RE: gp130 Cytokines are positive signals triggering changes in gene expression and axon outgrowth in peripheral neurons following injury. Front Mol Neurosci 2012, 4:62

55. Lu X, Richardson PM: Inflammation near the nerve cell body enhances axonal regeneration. J Neurosci 1991, 11:972-978

56. Yin Y, Henzl MT, Lorber B, Nakazawa T, Thomas TT, Jiang F, Langer R, Benowitz LI: Oncomodulin is a macrophage-derived signal for axon regeneration in retinal ganglion cells. Nat Neurosci 2006, 9: $843-852$

57. Gao Y, Nikulina E, Mellado W, Filbin MT: Neurotrophins elevate cAMP to reach a threshold required to overcome inhibition by MAG through extracellular signal-regulated kinase-dependent inhibition of phosphodiesterase. J Neurosci 2003, 23:11770-11777

58. Udina E, Furey M, Busch S, Silver J, Gordon T, Fouad K: Electrical stimulation of intact peripheral sensory axons in rats promotes outgrowth of their central projections. Exp Neurol 2008, 210:238-247

59. Park KK, Liu K, Hu Y, Smith PD, Wang C, Cai B, Xu B, Connolly L, Kramvis I, Sahin M, He Z: Promoting axon regeneration in the adult CNS by modulation of the PTEN/mTOR pathway. Science 2008, 322:963-966

60. Liu K, Lu Y, Lee JK, Samara R, Willenberg R, Sears-Kraxberger I, Tedeschi A, Park KK, Jin D, Cai B, Xu B, Connolly L, Steward O, Zheng B, He Z: PTEN deletion enhances the regenerative ability of adult corticospinal neurons. Nat Neurosci 2010, 13:1075-1081

61. Gutilla EA, Buyukozturk MM, Steward O: Long-term consequences of conditional genetic deletion of PTEN in the sensorimotor cortex of neonatal mice. Exp Neurol 2016, 279:27-39

62. David S, Aguayo AJ: Axonal elongation into peripheral nervous system "bridges" after central nervous system injury in adult rats. Science 1981, 214:931-933

63. Cregg JM, DePaul MA, Filous AR, Lang BT, Tran A, Silver J: Functional regeneration beyond the glial scar. Exp Neurol 2014, 253: 197-207

64. Rudge JS, Silver J: Inhibition of neurite outgrowth on astroglial scars in vitro. J Neurosci 1990, 10:3594-3603

65. Faulkner JR, Herrmann JE, Woo MJ, Tansey KE, Doan NB, Sofroniew MV: Reactive astrocytes protect tissue and preserve function after spinal cord injury. J Neurosci 2004, 24:2143-2155

66. Anderson MA, Burda JE, Ren Y, Ao Y, O'Shea TM, Kawaguchi R, Coppola G, Khakh BS, Deming TJ, Sofroniew MV: Astrocyte scar formation aids CNS axon regeneration. Nature 2016, 532:195-200

67. Silver J, Miller JH: Regeneration beyond the glial scar. Nat Rev Neurosci 2004, 5:146-156

68. McKeon RJ, Jurynec MJ, Buck CR: The chondroitin sulfate proteoglycans neurocan and phosphacan are expressed by reactive astrocytes in the chronic CNS glial scar. J Neurosci 1999, 19:10778-10788

69. Tang X, Davies JE, Davies SJA: Changes in distribution, cell associations, and protein expression levels of NG2, neurocan, phosphacan, brevican, versican V2, and tenascin-C during acute to chronic maturation of spinal cord scar tissue. J Neurosci Res 2003, 71:427-444

70. Snow DM, Steindler DA, Silver J: Molecular and cellular characterization of the glial roof plate of the spinal cord and optic tectum: a possible role for a proteoglycan in the development of an axon barrier. Dev Biol 1990, 138:359-376

71. Matthews RT, Kelly GM, Zerillo CA, Gray G, Tiemeyer M, Hockfield S: Aggrecan glycoforms contribute to the molecular heterogeneity of perineuronal nets. J Neurosci 2002, 22:7536-7547

72. Bradbury EJ, Moon LDF, Popat RJ, King VR, Bennett GS, Patel PN, Fawcett JW, McMahon SB: Chondroitinase ABC promotes functional recovery after spinal cord injury. Nature 2002, 416:636-640

73. Siebert JR, Osterhout DJ: The inhibitory effects of chondroitin sulfate proteoglycans on oligodendrocytes. J Neurochem 2011, 119:176-188

74. Keough MB, Rogers JA, Zhang P, Jensen SK, Stephenson EL, Chen T, Hurlbert MG, Lau LW, Rawji KS, Plemel JR, Koch M, Ling C-C, Yong VW: An inhibitor of chondroitin sulfate proteoglycan synthesis promotes central nervous system remyelination. Nat Commun 2016, 7:11312

75. Gilbert RJ, McKeon RJ, Darr A, Calabro A, Hascall VC, Bellamkonda RV: CS-4,6 is differentially upregulated in glial scar and is a potent inhibitor of neurite extension. Mol Cell Neurosci 2005, 29:545-558

76. McKeon RJ, Höke A, Silver J: Injury-induced proteoglycans inhibit the potential for laminin-mediated axon growth on astrocytic scars. Exp Neurol 1995, 136:32-43

77. Shen Y, Tenney AP, Busch SA, Horn KP, Cuascut FX, Liu K, He Z, Silver J, Flanagan JG: PTPsigma is a receptor for chondroitin sulfate proteoglycan, an inhibitor of neural regeneration. Science 2009, 326 : 592-596

78. Fisher D, Xing B, Dill J, Li H, Hoang HH, Zhao Z, Yang X-L, Bachoo R, Cannon S, Longo FM, Sheng M, Silver J, Li S: Leukocyte common antigen-related phosphatase is a functional receptor for chondroitin sulfate proteoglycan axon growth inhibitors. J Neurosci 2011, 31:14051-14066

79. Duan Y, Giger RJ: A new role for RPTPsigma in spinal cord injury: signaling chondroitin sulfate proteoglycan inhibition. Sci Signal 2010, 3:pe6

80. Dickendesher TL, Baldwin KT, Mironova YA, Koriyama Y, Raiker SJ, Askew KL, Wood A, Geoffroy CG, Zheng B, Liepmann CD, Katagiri Y, Benowitz LI, Geller HM, Giger RJ: NgR1 and NgR3 are receptors for chondroitin sulfate proteoglycans. Nat Neurosci 2012, 15:703-712

81. Monnier PP, Sierra A, Schwab JM, Henke-Fahle S, Mueller BK: The Rho/ROCK pathway mediates neurite growth-inhibitory activity associated with the chondroitin sulfate proteoglycans of the CNS glial scar. Mol Cell Neurosci 2003, 22:319-330

82. Sivasankaran R, Pei J, Wang KC, Zhang YP, Shields CB, Xu X-M, $\mathrm{He} Z$ : PKC mediates inhibitory effects of myelin and chondroitin sulfate proteoglycans on axonal regeneration. Nat Neurosci 2004, 7:261-268

83. Koprivica V, Cho K-S, Park JB, Yiu G, Atwal J, Gore B, Kim JA, Lin E, Tessier-Lavigne M, Chen DF, He Z: EGFR activation mediates inhibition of axon regeneration by myelin and chondroitin sulfate proteoglycans. Science 2005, 310:106-110

84. Yick LW, Wu W, So KF, Yip HK, Shum DK: Chondroitinase ABC promotes axonal regeneration of Clarke's neurons after spinal cord injury. Neuroreport 2000, 11:1063-1067

85. Yick L-W, So K-F, Cheung P-T, Wu W-T: Lithium chloride reinforces the regeneration-promoting effect of chondroitinase $\mathrm{ABC}$ on rubrospinal neurons after spinal cord injury. J Neurotrauma 2004, 21: 932-943

86. Steinmetz MP, Horn KP, Tom VJ, Miller JH, Busch SA, Nair D, Silver DJ, Silver J: Chronic enhancement of the intrinsic growth capacity of sensory neurons combined with the degradation of inhibitory proteoglycans allows functional regeneration of sensory axons through the dorsal root entry zone in the mammalian spinal cord. J Neurosci 2005, 25:8066-8076 
87. Zhao R-R, Fawcett JW: Combination treatment with chondroitinase ABC in spinal cord injury: breaking the barrier. Neurosci Bull 2013, 29:477-483

88. Filous AR, Miller JH, Coulson-Thomas YM, Horn KP, Alilain WJ, Silver J: Immature astrocytes promote CNS axonal regeneration when combined with chondroitinase ABC. Dev Neurobiol 2010, 70:826-841

89. Bradbury EJ, Carter LM: Manipulating the glial scar: chondroitinase ABC as a therapy for spinal cord injury. Brain Res Bull 2011, 84:306-316

90. Carlstedt T: Regenerating axons form nerve terminals at astrocytes. Brain Res 1985, 347:188-191

91. Liuzzi FJ, Lasek RJ: Astrocytes block axonal regeneration in mammals by activating the physiological stop pathway. Science 1987 , 237:642-645

92. Nishiyama A, Chang A, Trapp BD: NG2 + glial cells: a novel glial cell population in the adult brain. J Neuropathol Exp Neurol 1999, 58: $1113-1124$

93. Di Maio A, Skuba A, Himes BT, Bhagat SL, Hyun JK, Tessler A, Bishop D, Son Y-J: In vivo imaging of dorsal root regeneration: rapid immobilization and presynaptic differentiation at the CNS/PNS border. J Neurosci 2011, 31:4569-4582

94. Busch SA, Horn KP, Cuascut FX, Hawthorne AL, Bai L, Miller RH Silver J: Adult NG2 + cells are permissive to neurite outgrowth and stabilize sensory axons during macrophage-induced axonal dieback after spinal cord injury. J Neurosci 2010, 30:255-265

95. McTigue DM, Tripathi R, Wei P: NG2 colocalizes with axons and is expressed by a mixed cell population in spinal cord lesions. J Neuropathol Exp Neurol 2006, 65:406-420

96. Lang BT, Cregg JM, DePaul MA, Tran AP, Xu K, Dyck SM, Madalena KM, Brown BP, Weng Y-L, Li S, Karimi-Abdolrezaee S, Busch SA, Shen Y, Silver J: Modulation of the proteoglycan receptor PTP $\sigma$ promotes recovery after spinal cord injury. Nature 2015, 518:404-408

97. Schwab ME, Caroni P: Oligodendrocytes and CNS myelin are nonpermissive substrates for neurite growth and fibroblast spreading in vitro. J Neurosci 1988, 8:2381-2393

98. McKerracher L, David S, Jackson DL, Kottis V, Dunn RJ, Braun PE: Identification of myelin-associated glycoprotein as a major myelinderived inhibitor of neurite growth. Neuron 1994, 13:805-811

99. Mukhopadhyay G, Doherty P, Walsh FS, Crocker PR, Filbin MT: A novel role for myelin-associated glycoprotein as an inhibitor of axonal regeneration. Neuron 1994, 13:757-767

100. Kottis V, Thibault P, Mikol D, Xiao Z-C, Zhang R, Dergham P, Braun PE: Oligodendrocyte-myelin glycoprotein (OMgp) is an inhibitor of neurite outgrowth. J Neurochem 2002, 82:1566-1569

101. Wang KC, Koprivica V, Kim JA, Sivasankaran R, Guo Y, Neve RL, He Z: Oligodendrocyte-myelin glycoprotein is a Nogo receptor ligand that inhibits neurite outgrowth. Nature 2002, 417:941-944

102. Chen MS, Huber AB, van der Haar ME, Frank M, Schnell L, Spillmann AA, Christ F, Schwab ME: Nogo-A is a myelin-associated neurite outgrowth inhibitor and an antigen for monoclonal antibody IN-1. Nature 2000, 403:434-439

103. Schwab ME: Nogo and axon regeneration. Curr Opin Neurobiol 2004, 14:118-124

104. Silver J: Much ado about Nogo. Neuron 2010, 66:619-621

105. Lee JK, Chan AF, Luu SM, Zhu Y, Ho C, Tessier-Lavigne M, Zheng B: Reassessment of corticospinal tract regeneration in Nogodeficient mice. J Neurosci 2009, 29:8649-8654

106. Lee JK, Geoffroy CG, Chan AF, Tolentino KE, Crawford MJ, Leal MA, Kang B, Zheng B: Assessing spinal axon regeneration and sprouting in Nogo-, MAG-, and OMgp-deficient mice. Neuron 2010, 66:663-670

107. Geoffroy CG, Zheng B: Myelin-associated inhibitors in axonal growth after CNS injury. Curr Opin Neurobiol 2014, 27:31-38

108. Monnier PP, Sierra A, Macchi P, Deitinghoff L, Andersen JS, Mann M, Flad M, Hornberger MR, Stahl B, Bonhoeffer F, Mueller BK: RGM is a repulsive guidance molecule for retinal axons. Nature 2002, 419:392-395

109. Rajagopalan S, Deitinghoff L, Davis D, Conrad S, Skutella T, Chedotal A, Mueller BK, Strittmatter SM: Neogenin mediates the action of repulsive guidance molecule. Nat Cell Biol 2004, 6: $756-762$

110. Schwab JM, Conrad S, Monnier PP, Julien S, Mueller BK, Schluesener HJ: Spinal cord injury-induced lesional expression of the repulsive guidance molecule (RGM). Eur J Neurosci 2005, 21: $1569-1576$

111. Apostolova I, Irintchev A, Schachner M: Tenascin-R restricts posttraumatic remodeling of motoneuron innervation and functional recovery after spinal cord injury in adult mice. J Neurosci 2006, 26 $7849-7859$

112. Hagino $\mathrm{S}$, Iseki $\mathrm{K}$, Mori $\mathrm{T}$, Zhang $\mathrm{Y}$, Hikake $\mathrm{T}$, Yokoya $\mathrm{S}$, Takeuchi M, Hasimoto H, Kikuchi S, Wanaka A: Slit and glypican-1 mRNAs are coexpressed in the reactive astrocytes of the injured adult brain. Glia 2003, 42:130-138

113. Bundesen LQ, Scheel TA, Bregman BS, Kromer LF: Ephrin-B2 and EphB2 regulation of astrocyte-meningeal fibroblast interactions in response to spinal cord lesions in adult rats. J Neurosci 2003, 23:7789-7800

114. Benson MD, Romero MI, Lush ME, Lu QR, Henkemeyer M, Parada LF: Ephrin-B3 is a myelin-based inhibitor of neurite outgrowth. Proc Natl Acad Sci U S A 2005, 102:10694-10699

115. Fabes J, Anderson P, Brennan C, Bolsover S: Regenerationenhancing effects of EphA4 blocking peptide following corticospinal tract injury in adult rat spinal cord. Eur J Neurosci 2007, 26: 2496-2505

116. Reza JN, Gavazzi I, Cohen J: Neuropilin-1 is expressed on adult mammalian dorsal root ganglion neurons and mediates semaphorin3a/collapsin-1-induced growth cone collapse by small diameter sensory afferents. Mol Cell Neurosci 1999, 14:317-326

117. Pasterkamp RJ, Verhaagen J: Semaphorins in axon regeneration: developmental guidance molecules gone wrong? Philos Trans R Soc Lond B Biol Sci 2006, 361:1499-1511

118. Kikuchi K, Kishino A, Konishi O, Kumagai K, Hosotani N, Saji I, Nakayama C, Kimura T: In vitro and in vivo characterization of a novel semaphorin 3A inhibitor, SM-216289 or xanthofulvin. J Biol Chem 2003, 278:42985-42991

119. Kaneko S, Iwanami A, Nakamura M, Kishino A, Kikuchi K, Shibata S, Okano HJ, Ikegami T, Moriya A, Konishi O, Nakayama C, Kumagai K, Kimura T, Sato Y, Goshima Y, Taniguchi M, Ito M, He Z, Toyama Y, Okano H: A selective Sema3A inhibitor enhances regenerative responses and functional recovery of the injured spinal cord. Nat Med 2006, 12:1380-1389

120. Wang B, Zhang N, Qian K-X, Geng J-G: Conserved molecular players for axon guidance and angiogenesis. Curr Protein Pept Sci 2005, 6:473-478

121. Suzuki K, Kumanogoh A, Kikutani H: Semaphorins and their receptors in immune cell interactions. Nat Immunol 2008, 9:17-23

122. Bagnard D, Sainturet N, Meyronet D, Perraut M, Miehe M, Roussel G, Aunis D, Belin MF, Thomasset N: Differential MAP kinases activation during semaphorin3A-induced repulsion or apoptosis of neural progenitor cells. Mol Cell Neurosci 2004, 25: $722-731$

123. Giraudon P, Vincent P, Vuaillat C, Verlaeten O, Cartier L, MarieCardine A, Mutin M, Bensussan A, Belin M-F, Boumsell L: Semaphorin CD100 from activated $\mathrm{T}$ lymphocytes induces process extension collapse in oligodendrocytes and death of immature neural cells. J Immunol 1950, 2004:1246-1255

124. Ben-Zvi A, Manor O, Schachner M, Yaron A, Tessier-Lavigne M, Behar O: The Semaphorin receptor PlexinA3 mediates neuronal apoptosis during dorsal root ganglia development. J Neurosci 2008 , 28:12427-12432

125. Hollis ER, Ishiko N, Yu T, Lu C-C, Haimovich A, Tolentino K, Richman A, Tury A, Wang S-H, Pessian M, Jo E, Kolodkin A, Zou Y: Ryk controls remapping of motor cortex during functional recovery after spinal cord injury. Nat Neurosci 2016, 19:697-705

126. Aguayo AJ, David S, Bray GM: Influences of the glial environment on the elongation of axons after injury: transplantation studies in adult rodents. J Exp Biol 1981, 95:231-240 